\title{
Article length bias in journal rankings
}

Citation for published version (APA):

Kóczy, L. Á., Nichifor, A., \& Strobel, M. (2009). Article length bias in journal rankings. METEOR, Maastricht University School of Business and Economics. METEOR Research Memorandum No. 016 https://doi.org/10.26481/umamet.2009016

Document status and date:

Published: 01/01/2009

DOI:

10.26481/umamet.2009016

Document Version:

Publisher's PDF, also known as Version of record

\section{Please check the document version of this publication:}

- A submitted manuscript is the version of the article upon submission and before peer-review. There can be important differences between the submitted version and the official published version of record.

People interested in the research are advised to contact the author for the final version of the publication, or visit the DOI to the publisher's website.

- The final author version and the galley proof are versions of the publication after peer review.

- The final published version features the final layout of the paper including the volume, issue and page numbers.

Link to publication

\footnotetext{
General rights rights.

- You may freely distribute the URL identifying the publication in the public portal. please follow below link for the End User Agreement:

www.umlib.nl/taverne-license

Take down policy

If you believe that this document breaches copyright please contact us at:

repository@maastrichtuniversity.nl

providing details and we will investigate your claim.
}

Copyright and moral rights for the publications made accessible in the public portal are retained by the authors and/or other copyright owners and it is a condition of accessing publications that users recognise and abide by the legal requirements associated with these

- Users may download and print one copy of any publication from the public portal for the purpose of private study or research.

- You may not further distribute the material or use it for any profit-making activity or commercial gain

If the publication is distributed under the terms of Article $25 \mathrm{fa}$ of the Dutch Copyright Act, indicated by the "Taverne" license above, 


\section{Maastricht University}

László Á. Kóczy, Alexandru Nichifor, Martin Strobel

Article length bias in journal rankings

$\mathrm{RM} / 09 / 016$

\section{METEOR}

Faculty of Economics and Business Administration Maastricht Research School of Economics

of Technology and Organization

\section{P.O. Box 616}

NL - 6200 MD Maastricht

The Netherlands 


\title{
Article length bias in journal rankings*
}

\author{
László Á. Kóczy ${ }^{\dagger} \quad$ Alexandru Nichifor ${ }^{\ddagger}$ Martin Strobel ${ }^{\S}$
}

\begin{abstract}
The quality of publications, approximated by the containing journal's quality indicator, is often the basis for hire and promotion in academic and research positions. Over the years a handful of ranking methods have been proposed. Discussing the most prominent methods we show that they are inherently biased against journals publishing short papers.
\end{abstract}

Keywords: quality ranking, paper length, impact factor, invariant method, LP method

\section{Introduction}

The last decades saw an explosion in the number of journals. Libraries face higher subscription fees and must allocate budgets in an efficient way. Researchers find it more and more difficult to keep up with the growing literature even in narrow fields. Funding and promotion decisions are often taken considering researchers' publications which are becoming increasingly difficult to evaluate and compare. All these developments contribute to the growing interest in objective measures of journal quality.

The ranking of journals has long been dominated by the Impact Factor (Garfield, 1955) although numerous alternative measures have been introduced, such as the invariant method (Pinski and Narin, 1976; Palacios-Huerta

*We thank Çağatay Kayı and Bettina Klaus for helpful comments. Kóczy thanks funding from OTKA under grant NF-72610; Nichifor thanks the Netherlands Organisation for Scientific Research (NWO) for its support under grant VIDI-452-06-013; Strobel thanks the funding by METEOR.

$\dagger$ Keleti Faculty of Economics, Budapest Tech, Tavaszmező u. 15-17., H-1084 Budapest and Maastricht University. Email: koczy.laszlo@kgk.bmf .hu.

$\ddagger$ Department of Economics, Maastricht University, P.O.Box 616, NL-6200MD Maastricht. Email: a.nichifor@algec.unimaas.nl.

$\S$ Department of Economics, Maastricht University, P.O.Box 616, NL-6200MD Maastricht. Emails: m.strobel@algec.unimaas.nl. 
and Volij, 2004), the LP method (Liebowitz and Palmer, 1984; Laband and Piette, 1994; Kalaitzidakis, Mamuneas, and Stengos, 2003) and the H-index (Hirsch, 2004; Braun, Glänzel, and Schubert, 2005). These methods generated many variations, the best known being the PageRank (Brin and Page, 1998) algorithm which plays an important part in how Google ranks web sites.

While most of these methods have been intuitively motivated, if at all, Palacios-Huerta and Volij (2004) presented an axiomatization for the invariant method from a descriptive perspective. That is, they find a set of requirements that fully characterizes the invariant method.

Some of these properties are invariance properties that allow the comparison of journals with different characteristics and from different fields. Yet, a property that affects also journals rankings within the same discipline, invariance to article-splitting, requiring neutrality with respect to the length of articles, has not been studied. We introduce this property and show that the ranking methods above are not invariant to article-splitting, but are biased against journals publishing short articles, exposition notes or letters.

\section{Ranking Methods}

Let $\mathbb{J}$ be the universe of journals and $\mathcal{J}$ be the set of all non-empty finite subsets of $\mathbb{J}$. Let $J \in \mathcal{J}, j \in J$ and let $a_{j}$ denote the number of articles published in $j$. For each $i, j \in J, c_{i j}$ represents the number of citations to journal $i$ by journal $j$, that is, the number of references made by journal $j$ to journal $i$. Let us consider the citation matrix a $|J| \times|J|$ nonnegative matrix, $C=\left\{c_{i j}\right\}_{i, j \in J}$ and let $c_{j}=\sum_{i \in J} c_{i j}$ be the total number of citations made by $j$.

Definition 1. A ranking problem is a triple $(J, a, C)$ consisting of a finite set of journals $J \in \mathcal{J}$, a vector $a \in \mathbb{N}^{|J|}$ containing the number of published articles and a citation matrix $C=\left\{c_{i j}\right\}_{i, j \in J}$.

Let $\mathcal{R}$ denote the set of ranking problems. A cardinal ranking of the journals in $J$ is given by a transposed valuations vector $v^{T}=\left(v_{1}, v_{2}, \ldots, v_{|J|}\right)$, where $v_{i}>0$.

Definition 2. A ranking method $\phi$ maps a ranking problem $(J, a, C) \in \mathcal{R}$ to a vector of valuations $v \in \mathbb{R}_{++}^{|J|}$.

A ranking method induces a weak ordering of the journals via the ranking rule $i \succcurlyeq j$ if and only if $v_{i} \geq v_{j}$. Ties, i.e., $i \succcurlyeq j$ and $j \succcurlyeq i$, are allowed, but only occur if $v_{i}=v_{j}$. 
Definition 3. The impact factor (Garfield, 1955) ranks according to $\mathrm{IF}_{j}=$ $\frac{\sum_{i \in J} c_{j i}}{a_{j}}$, where vector a and matrix $C$ contain data for a two-year period.

Before we present the next two ranking methods, we need an additional assumption and some extra notation. We require the citation matrix $C$ to be irreducible: there is no partition of the set of journals $J$ in two sets $J_{1}$ and $J_{2}$ such that [there are no inter partition citations] or [all inter partition citations are unidirectional, say from journals in $J_{2}$ to journals in $\left.J_{1}\right]$. Let $A$ and $D_{C}$ be diagonal matrices with $\left\{a_{j}\right\}_{j \in J}$ and $\left\{c_{j}\right\}_{j \in J}$ along the diagonal.

Definition 4. The invariant method (Pinski and Narin, 1976) ranks according to the vector $v$ that solves

$$
A^{-1} C D_{C}^{-1} A v=v .
$$

Definition 5. The LP method (Liebowitz and Palmer, 1984) ranks according to the vector $v$ that solves

$$
A^{-1} C v=v
$$

It is known that both the invariant method and the LP method are well defined for irreducible matrices (Palacios-Huerta and Volij, 2004).

\section{Article-Splitting}

Next we introduce a basic desirable property of a ranking method: invariance to article-splitting. When we refer to an article's citations, we consider both citations sent (that we interpret as an article's "consumption") and received (that we interpret as an article's "production" which was consumed by other articles). We do not measure the length of a paper in terms of pages or characters. Length is indicated by the number of citations sent and received, which, we assume are both evenly spread in a journal. In particular, we assume that if a paper is split into $k$ sub-papers, the citations are split evenly among them. ${ }^{1}$ Our invariance property requires that having the split ex-post or ex-ante should make no difference. That is, splitting the citations between the sections of a paper, or publishing sub-papers, leave the ranking unchanged.

Formally, let $\lambda_{j} \in \mathbb{R}, \lambda_{j}>1$, be a split factor and consider two ranking problems $\left\{(J, a, C),\left(J, a^{\prime}, C\right)\right\} \subseteq \mathcal{R}$ where for some journal $j \in J, a_{j}^{\prime}=\lambda_{j} a_{j}$ and for all other journals $i \neq j, a_{i}^{\prime}=a_{i}$.

\footnotetext{
${ }^{1}$ Conversely, if a set of $k$ articles with no overlapping citations and published in the same journal are merged into a single paper, like a survey or a book, then the resulting publication collects all citations.
} 
Definition 6. A ranking method $\phi$ is invariant to article-splitting if

$$
\phi(J, a, C)=\phi\left(J, a^{\prime}, C\right) .
$$

Observe that the citation matrix is not affected: the number of citations does not change, they are only distributed among more papers. The property thus relates ranking problems implicating journals having similar citation patterns but publishing different numbers of articles.

Definition 7. A ranking method $\phi$ is biased against article-splitting if

$$
\phi_{j}(J, a, C)>\phi_{j}\left(J, a^{\prime}, C\right) .
$$

In the following we show that none of the listed ranking methods is invariant to article-splitting.

Proposition 1. The impact factor is not invariant to article-splitting.

Proof. Given journal $j$ has a valuation $\operatorname{IF}_{j}$ for problem $(J, a, C)$ covering data for the past two years, consider a modification of the problem where some of $j$ 's articles are split and hence $a_{j}^{\prime}=\lambda_{j} a_{j}$ with $\lambda_{j}>1$, while $a_{i}^{\prime}=a_{i}$ for all $i \neq j$. Although this leaves the numerator unaffected, the number of articles goes up. $\mathrm{IF}_{j}^{\prime}=\frac{a_{j}}{a_{j}^{\prime}} \mathrm{IF}_{j}=\frac{1}{\lambda_{j}} \mathrm{IF}_{j}$, thus the impact factor decreases.

Proposition 2. The invariant method is not invariant to article-splitting.

Proof. Let $v_{j}$ be the valuation of journal $j$ for problem $(J, a, C)$. Then $v$ solves Equation 1. Now consider a modification of the problem where some of $j$ 's articles are split and hence $a_{j}^{\prime}=\lambda_{j} a_{j}$ with $\lambda_{j}>1$, while $a_{i}^{\prime}=a_{i}$ for all $i \neq j$. Then $v^{\prime}$ defined as $v_{j}^{\prime}=\frac{1}{\lambda_{j}} v_{j}$ and $v_{i}^{\prime}=v_{i}$ for $i \neq j$ is the solution of Equation 1, that is $A^{\prime-1} C D_{C}^{-1} A^{\prime} v^{\prime}=v^{\prime}$. In order to see this, pre-multiply by $A^{\prime}$ and observe that $A^{\prime} v^{\prime}=A v$. Finally observe that as $\lambda_{j}>0, v_{j}^{\prime}<v_{j}$, while the valuations of other journals have not changed.

Proposition 3. The LP method is not invariant to article-splitting.

Proof. Using a similar technique as Roy, Saberi, and Wan (2008), we show that an increase (decrease) in the number of articles of a journal will decrease (increase) its valuation. All else equal, let journal $j$ increase the number of its articles per issue from $a_{j}$ to $a_{j}^{\prime}$, i.e., $a_{j}^{\prime}=\lambda_{j} a_{j}$ with $\lambda_{j}>1$, while for all $i \neq j, a_{i}^{\prime}=a_{i}$. Thus, Equation 2 becomes:

$$
A^{\prime-1} C v^{\prime}=v^{\prime}
$$


Note that Equations 2 and 3 are algebraic eigenvalue problems. Let $\Gamma=A^{-1} C$ and $\Gamma^{\prime}=A^{\prime-1} C$. Let $\varrho(\Gamma)$ denote the spectral radius of $\Gamma$ and let $v$ denote the eigenvectors associated with $\varrho(\Gamma)$. Similarly, we use $\varrho\left(\Gamma^{\prime}\right), \Gamma^{\prime}$, $v^{\prime}$. Since the matrix $\Gamma$ is irreducible, $\Gamma^{\prime}$ is also irreducible and Equation 3 is well defined. Using the newly introduced notation, we rewrite Equations 2 and 3 as $\Gamma v=\varrho(\Gamma) v$ and $\Gamma^{\prime} v^{\prime}=\varrho\left(\Gamma^{\prime}\right) v^{\prime}$. Observe that $\Gamma$ and $\Gamma^{\prime}$ are obtained from the same citation matrix $C$ which is pre-multiplied by $A^{-1}$ respectively $A^{\prime-1}$ and that for all $i \in J, a_{i}^{\prime} \geq a_{i}$. Hence, $\Gamma^{\prime}$ is weakly smaller in every entry than $\Gamma$ and therefore $\varrho(\Gamma)=\varrho\left(\Gamma^{\prime}\right)+\delta$ for some $\delta>0$.

We scale $v^{\prime}$ such that $v_{j}^{\prime}=v_{j}$ and rewrite $v^{\prime T}$ as $\bar{v}^{T}=v^{T}-x^{T}=\left[v_{1}-\right.$ $\left.x_{1}, \ldots, v_{j}-x_{j}, \ldots, v_{i}-x_{i}\right]$ where $x \in \mathbb{R}^{|J|}$, such that $x_{j}=0$. Thus, $\Gamma^{\prime} \bar{v}=\varrho\left(\Gamma^{\prime}\right) \bar{v}$ and replacing $\bar{v}$ and $\varrho\left(\Gamma^{\prime}\right)$ :

$$
\Gamma^{\prime} v-\Gamma^{\prime} x=\varrho(\Gamma) v-\delta v-\varrho\left(\Gamma^{\prime}\right) x
$$

Let $v_{-j}, \bar{v}_{-j}, x_{-j}$ be the valuation vectors except for journal $j$. Similarly, let $\Gamma_{-j}$ and $\Gamma_{-j}^{\prime}$ be the matrices $\Gamma$ and $\Gamma^{\prime}$ where we removed row and column $j$ and note that $\Gamma_{-j}=\Gamma_{-j}^{\prime}$. Dropping the $j$ 'th equation from the system of Equations 4 and using that $\Gamma v=\varrho(\Gamma) v$ we obtain:

$$
\Gamma_{-j} x_{-j}=\delta v_{-j}+\varrho\left(\Gamma^{\prime}\right) x_{-j} .
$$

which can be rearranged to $\left(\varrho\left(\Gamma^{\prime}\right) I-\Gamma_{-j}\right) x_{-j}=-\delta v_{-j}$. Minc (1988, Theorem 5.1 and Theorem 5.2, Chapter 1) shows that the spectral radius of an irreducible matrix is greater than the spectral radius of any of its submatrices. Hence, $\varrho\left(\Gamma^{\prime}\right) \geq \varrho\left(\Gamma_{-j}^{\prime}\right)=\varrho\left(\Gamma_{-j}\right)$. The matrix $M=\left(\varrho\left(\Gamma^{\prime}\right) I-\Gamma_{-j}\right)$ is an M-matrix. Therefore, $M^{-1}$ is positive. (For a reminder of M-matrices and their properties see Minc, 1988, Definition 4.1, Theorem 4.5, Chapter 6). Observing that $v_{-j}$ is positive, $x_{-j}$ has to be negative. Hence, $\bar{v}_{j}=v_{j}$ and for all $i \neq j, \bar{v}_{i}>v_{i}$. Rescaling $\bar{v}$ to $v^{\prime}$, we have $\frac{v_{j}^{\prime}}{v_{i}^{\prime}}<\frac{v_{j}}{v_{i}}$.

Theorem 1. The impact factor, the invariant method and the LP method are biased against article-splitting.

Proof. We have shown that for the impact factor and for the invariant method the valuation of a journal $j$ whose articles are split into $\lambda_{j}$ decreases by a factor of $\frac{1}{\lambda_{j}}$. Note that for an appropriate choice of $\lambda_{j}$ it can be arbitrarily low. In particular, it can be lower than the valuation of the journal ranked next, thus changing also the relative order of the journals. For the LP method, we have shown that an increase in the number of articles of journal $j$ decreases its relative weight that can lead to the same effect. 
The following example shows that the bias against article-splitting affecting the ranking methods might also induce changes in the relative ordering of the journals:

Example 1. Let $J=\left\{j_{1}, j_{2}, j_{3}\right\}, a=(2,2,3), a^{\prime}=(4,2,3)$ and define $C$ as:

$$
C=\left(\begin{array}{ccc}
12 & 8 & 4 \\
6 & 10 & 2 \\
3 & 3 & 9
\end{array}\right)
$$

Let $R=(J, a, C)$ and $R^{\prime}=\left(J, a^{\prime}, C\right)$ be two ranking problems and note that the only difference between $R$ and $R^{\prime}$ is that $a_{1}^{\prime}=\lambda_{1} a_{1}$, with $\lambda_{1}=2$. For each problem $R$ and $R^{\prime}$, the following table presents the vector of valuations produced by each of the ranking methods investigated. ${ }^{2}$

\begin{tabular}{|c|cc|cc|cc|}
\hline & $\phi_{I F}(R)$ & $\phi_{I F}\left(R^{\prime}\right)$ & $\phi_{I M}(R)$ & $\phi_{I M}\left(R^{\prime}\right)$ & $\phi_{L P}(R)$ & $\phi_{L P}(R)$ \\
\hline$j_{1}$ & 0.46 & 0.30 & 0.48 & 0.31 & 0.50 & 0.29 \\
$j_{2}$ & 0.35 & 0.45 & 0.33 & 0.44 & 0.37 & 0.51 \\
$j_{3}$ & 0.19 & 0.25 & 0.19 & 0.25 & 0.13 & 0.20 \\
\hline
\end{tabular}

Table 1: Article-splitting bias in ranking methods inducing changes in the relative ordering of the journals.

Note that for $R$, all ranking methods induce the ordering $j_{1} \succ j_{2} \succ j_{3}$, while for $R^{\prime}$, all ranking methods induce the ordering $j_{2} \succ j_{1} \succ j_{3}$.

\section{Conclusion}

We find that the most widely used methods to rank academic journals share a common drawback as they cannot distinguish quality from quantity at the paper level, which might create a bias against journals with briefer communications. One must therefore use and interpret those rankings with care when estimating the quality of journals.

Not all ranking methods are subject to such bias. In the case of the $\mathrm{H}$ index (Hirsch, 2004; Braun, Glänzel, and Schubert, 2005) it is easy to see that article-splitting has an ambiguous effect, while the tournament method (Kóczy and Strobel, 2007) is by definition invariant to article-splitting. Further work is due to understand more about the properties and interpretations of different ranking methods.

\footnotetext{
${ }^{2}$ Since in this example we are interested only in relative values, for each method we have normalized the vector of valuations so that they add up to 1 .
} 


\section{References}

Braun, T., W. Glänzel, and A. Schubert (2005): "A Hirsch-Type Index for Journals," The Scientist, 19(22), 8.

Brin, S., And L. PAge (1998): "The Anatomy of a Large-Scale Hypertextual Web Search Engine," Computer Networks and ISDN Systems, 30(1-2), $107-117$.

Garfield, E. (1955): "Citation Indexes to Science: A New Dimension in Documentation through Association of Ideas," Science, 122(3159), 108111.

Hirsch, J. E. (2004): "An Index to Quantify an Individual's Scientific Research Output," Proceedings of the National Academy of Sciences, 102(46), 16569-16572.

Kalaitzidakis, P., T. P. Mamuneas, and T. Stengos (2003): "Rankings of Academic Journals and Institutions in Economics," Journal of the European Economic Association, 1(6), 1346-1366.

Kóczy, L. Á., And M. Strobel (2007): "Ranking Academic Journals by Tournament Methods," Mimeo.

Laband, D. N., And M. J. Piette (1994): "The Relative Impacts of Economics Journals: 1970-1990," Journal of Economic Literature, 32, 640666.

Liebowitz, S. J., And J. C. PAlmer (1984): "Assessing the Relative Impacts of Economics Journals," Journal of Economic Literature, 22(1), $77-88$.

Minc, H. (1988): Nonnegative Matrices. John Wiley and Sons, New York.

Palacios-Huerta, I., and O. VoliJ (2004): "The Measurement of Intellectual Influence," Econometrica, 72(3), 963-977.

Pinski, G., ANd F. NARin (1976): "Citation Influence for Journal Aggregates of Scientific Publications: Theory, with Application to the Literature of Physics," Information Processing \& Management, 12(5), 297-312.

Roy, S., A. Saberi, and Y. Wan (2008): "Majorization for the Dominant Eigenvector of a Nonnegative Matrix," American Control Conference, Westin Seattle Hotel, Seattle, Washington, USA, pp. 1965-1966. 